\title{
Modeling the hydrogeochemical evolution of brine in saline systems: case study of the Sabkha of Oum El Khialate in South East Tunisia
}

\author{
Nasri Nesrine ${ }^{1}$, Bouhlila Rachida ${ }^{1}$, Maarten W. Saaltink ${ }^{2}$, Pablo Gamazo ${ }^{3}$ \\ 1 Laboratoire de Modélisation en Hydraulique et Environnement, Ecole Nationale \\ d’Ingénieur de Tunis, Université Tunis El Manar. BP 37, Le Belvedere, 1002 Tunis \\ Tunisia, email: nasri.hydro@gmail.com \\ 2 GHS, Dept Geotechnical Engineering and Geosciences, Universitat Politecnica de \\ Catalunya, UPC-BarcelonaTech, c/Jordi Girona 1-3, 08034 Barcelona, Spain \\ ${ }^{3}$ Departamento del Agua, CENUR Noroeste, Universidad de la República, Gral. Rivera \\ 1350, 50000 Salto, Uruguay
}

\begin{abstract}
We studied the effects of evaporation and groundwater flow on the formation of salt minerals in the sabkha of Oum El Khialate in South East Tunisia, which contains large amounts of sulfate sodium mineral deposits. Due to the fact that there are no important surface water bodies present in this sabkha, transport of solutes is dominated by advection rather than mixing in lakes. For our study we used both analytical conservative and numerical reactive transport models. Results showed that salinity varies with distance and may reach very high levels near a watershed where the groundwater flux is zero. As a consequence, reactive transport simulations results showed that more minerals precipitate and water activity decreases values near this watershed. Model results also showed that a sequence of precipitating minerals could be deduced after 140000 years. From the boundary of the sabkha towards the watershed the mineral sequence was dolomite, gypsum, magnesite, bloedite, halite and mirabilite. It was found that the amounts as well as the mineral precipitation distribution strongly depend on salinity and rates of inflowing water.
\end{abstract}

Keywords: arid environment, sabkha, sulfate sodium, reactive transport, numerical model.

\section{Introduction}

The study of saline systems has various interests. It provides information about paleoclimate, sea level and sedimentological history (Rosen, 1994). Also saline systems contain valuable salt reserves, either as mineral precipitates or dissolved in the brine. Many salt deposits constitute economically important mineral stocks and have been exploited for the extraction of gypsum $\left(\mathrm{CaSO}_{4} \cdot 2 \mathrm{H}_{2} \mathrm{O}\right)$, halite $(\mathrm{NaCl})$, natron $\left(\mathrm{Na}_{2} \mathrm{CO}_{3}\right)$, mirabilite $\left(\mathrm{NaSO}_{4} \cdot 10 \mathrm{H}_{2} \mathrm{O}\right)$, and others (Dotsika et al., 2009; Kelly and Holmden 2001; 
García-Veigas et al., 2011). Salt layers have also been used for nuclear waste storage (Bouhlila, 1999).

The genesis of these deposits is controlled by hydrology, sedimentology, chemistry and brine mineralogy (Eugster, 1980). Smith (2000) describes different origins of salt systems such as connate salt from saline water trapped in sedimentary rocks, rock weathering, or sea water salt. Their formation is affected by processes of solute recycling, mineral precipitation and fractional dissolution (Dotsika et al., 2009). The inflowing water normally controls the brine chemistry. Salt minerals are precipitated during the process of evaporation, usually in depressions of high salinity, producing large amounts of evaporite minerals (Wood and Sanford, 1991).

The motivation of our study is the saline systems in Southern Tunisia such us Chott El Jerid, sabkha El Melah-Zarzis and Oum El Khialate. Geological, hydrogeological and geochemical research showed that these regions contain very significant natural brine reserves. For example, in the case of Oum El Khialate, the total reserves of mirabilite are about 16 Million tons (Guizani and Zarai, 2009). This sabkha is an example of a sulfate sodium deposit containing thenardite $\left(\mathrm{NaSO}_{4}\right)$ and mirabilite $\left(\mathrm{NaSO}_{4} \cdot 10 \mathrm{H}_{2} \mathrm{O}\right)$. These types of salt minerals are also found in the Great Plain of Canada (Last and Schweyen 1983), in the Salada Mediana in Spain (Valero-Garces et al. 2000) and in the Meyghan lake in Iran (Rahimpour-Bonab and Abdi, 2012). Wells (1923) gives a review of the uses and origins of sodium sulfate. It is commercially important for manufacturing kraft paper, detergent, ceramics and glass (Last, 1984; Khalili and Torabi, 2003). Sulfate sodium deposits are precipitated especially during cold seasons (Last, 1989; Valero-Garcea 2000; Orti et al. 2002). Their presence is related to the dissolution of gypsum and halite (Last 1992). Yagmurlu and Helvaci (1994) suggested that the sulfate-sodium deposit derived from alkaline volcanics and granites.

Reactive transport modeling is a useful tool for analyzing these processes in groundwater systems (Walter et al., 1994; Keatin and Bahr, 1998; Nields et al., 2008; Appelo and Rolle, 2010; Bea et al., 2010). Many applications to the hydrochemistry of salt water have been reported including multi-component reactive transport under variable density groundwater flow, the injection of carbon dioxide in saline aquifers and the impact of cation exchange on brine formation (Gomis, et al. 1995, Steefel et al. 2005, Mao et al. 2006, Audigane et al. 2007, Dalkhaa et al. 2013). Due to the nonlinearity and coupling of geochemical saline system, most saline reactive problems are solved using an implicit approach. This leads to a large number of transport equations and chemical reactions that must be solved simultaneously.

Many conceptual models based on balance of water and solutes have been developed in order to understand the formation processes of saline systems (Eugster and Jones, 1979; Sanford and Wood, 1991; Ayora et al., 2001; Yiechieli and Wood, 2002; Ingebritsen et al., 2006). These models aim to integrate all the information about the origin of water, chemical reactions and transport processes which control the evolution of a given system. Sanford and Wood (1991), based on solute mass balances, show the importance of the hydrological parameters on the chemical and mineralogical compositions of open and closed evaporate basins. The concentrations of salt minerals in a basin may increase according to the input concentration (Ingebritsen et al., 2006) or may decrease by the continuous dilution of the inflow water, depending on the inflow-evaporation ratio. The geochemistry of the sabkha is mainly controlled by evaporation, groundwater level fluctuation, and water and solute inflow (Rodriguez-Rodriguez et al., 2006). Yechieli 
and Wood (2002) elaborated a conceptual model of a coastal sabkha in order to determine the origin of water and solute. Results showed that the upward groundwater flux is the major source of solutes into the system and that the transfer of water and solute is controlled by the climate and the hydrogeological and chemical reactions (dissolution - precipitation, ion exchange and redox reactions).

Most geochemical modeling studies systems assume an ideally mixed system where concentrations are uniform in the whole modeled domain. This may be a valid assumption when the modeled domain is a lake with water evaporating from its surface. However, often the sabkha develops within an aquifer and mixing of solutes through dispersion is not high enough for allowing the assumption of an ideally mixed system. For such cases, 1D or 2D models that acknowledge advection and the spatial distribution of dissolved and precipitated salt concentrations are needed. Nield et al. (2008) developed 1D and 2D vertical models of groundwater beneath salt lakes to study convection due to density dependent flow. However they did not consider evaporation from the soil and considered the precipitation of only one mineral.

This paper aims to study the coupling effect of groundwater flow in advectiondominated high saline systems affected by evaporation. The evolution of the Sabkha of Oum El Khialate will be simulated applying 1D analytical conservative model, and 1D and $2 \mathrm{D}$ numerical reactive transport models. In section 2 a description of the sabkha is given. In section 3 two simple analytical models for conservative solutes are presented: one for an ideally mixed and one for an advection dominated system. This can provide a first understanding of the interaction between solute transport and evaporation and the spatial and temporal scales on which these processes take place. In section 4 1D and 2D numerical reactive transport models are presented. Finally, section 5 is dedicated to the conclusions.

\section{Site description}

Sabkha Oum El Khialate is located in South East Tunisia, $55 \mathrm{~km}$ from Tataouine and 65 $\mathrm{km}$ South West of Ben Guerdene (Fig. 1). It comprises an area of about $52 \mathrm{Km}^{2}$ at a latitude of $32^{\circ} 45^{\prime} \mathrm{N}$ and longitude of $10^{\circ} 53^{\prime}$. It is characterized by an arid type of climate with an average precipitation of $104 \mathrm{~mm} /$ year during 1956-2006. The mean temperature is $20.7^{\circ} \mathrm{C}$ while the potential evaporation exceeds $1106 \mathrm{~mm} /$ year (Baccar and Louhaichi, 2007).

The sabkha is a large shallow depression filled with recent Quaternary deposits. The aquifer of the basin is delimited at the bottom by fissured clay of the Mhira formation. The flow is from West to East and from South to North (Fig. 2). The map shows a piezometric depression towards sabkha Oum El Khialate. After rainfall events intermittent surface water is formed, but this quickly runoffs or infiltrates and no permanent surface water bodies such as lakes can be found.

The study area is characterized by a higher TDS in the center of the sabkha and with enrichment in brine especially mirabilite $\left(\mathrm{Na}_{2} \mathrm{SO}_{4} \cdot 10 \mathrm{H}_{2} \mathrm{O}\right)$. In a preliminary study the age and evolution of the brine was determined (ERI, 2010). The analytical model estimates the age of brine at 142000 years and the average concentration at $133 \mathrm{~g} / \mathrm{l}$. 


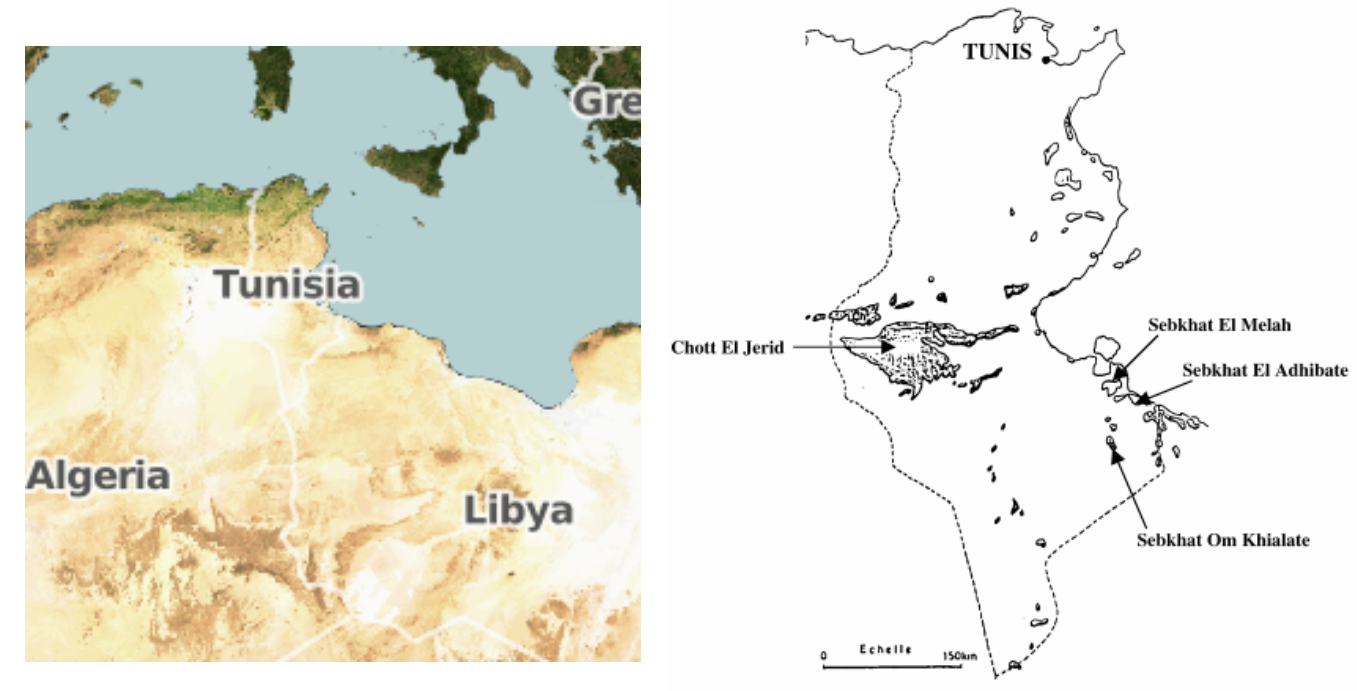

Fig.1. Location of the sabkha Oum El Khialate

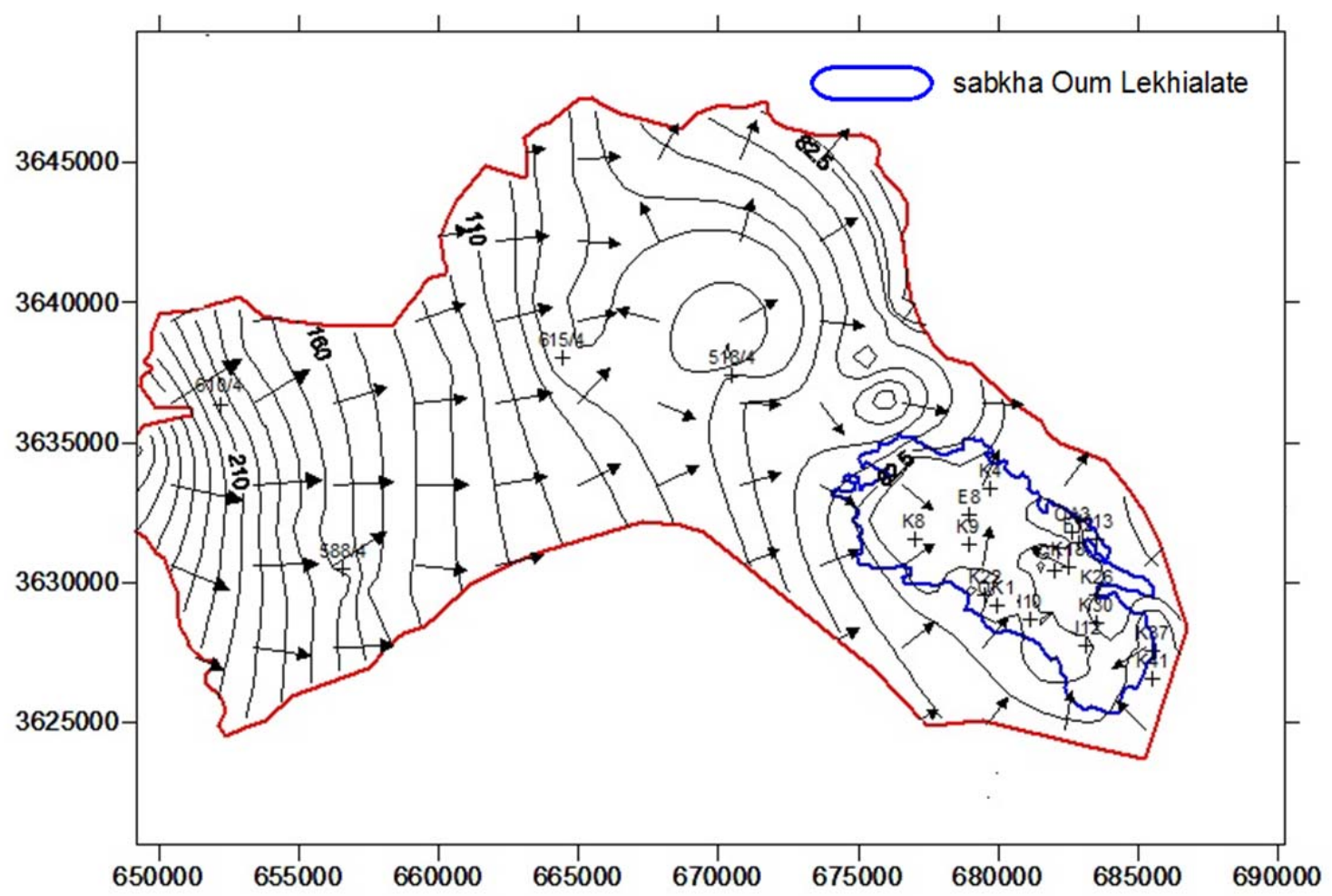

Fig. 2. Piezometric level of the catchment area (2007) 


\section{Analytical conservative models}

\subsection{Ideally mixed model}

We first present an ideally mixed model similar to that presented by Sanford and Wood (1991). We formulate a steady state water balance for the whole aquifer as follows:

$$
Q_{p}-Q_{e}+Q_{\text {in }}-Q_{\text {out }}=0
$$

where $Q_{p}$ is the average infiltration into the aquifer (average rainfall minus the surface runoff), $Q_{e}$ is the actual evaporation, $Q_{i n}$ is the groundwater flowing into the aquifer and $Q_{\text {out }}$ the groundwater flowing out of the aquifer. We formulate a transient solute mass balance as:

$$
V \frac{d c}{d t}=Q_{p} c_{p}+Q_{\text {in }} c_{\text {in }}-Q_{\text {out }} c
$$

where $\mathrm{V}$ is the volume of water in the aquifer $(V=S b \phi$, where $S$ is the surface area of the aquifer, $b$ its thickness and $\phi$ its porosity) $c$ the concentration of the solute in the aquifer and $c_{p}$, and $c_{i n}$ the concentrations in the infiltrating water and inflowing groundwater respectively. The solution of equation (2) is:

$$
c=\frac{Q_{p} c_{p}+Q_{\text {in }} c_{\text {in }}}{Q_{\text {out }}}\left(1-\exp \left(-\frac{Q_{\text {out }} t}{V}\right)\right)+c_{0} \exp \left(-\frac{Q_{\text {out }} t}{V}\right)
$$

where $c_{0}$ is the initial concentration. When time tends to infinite the system reach a steady state with a concentration, $c_{\infty}$, equal to:

$$
c_{\infty}=\frac{Q_{p} c_{p}+Q_{\text {in }} c_{\text {in }}}{Q_{\text {out }}}
$$

We can rewrite equation (3) as:

$$
c=c_{\infty}\left(1-\exp \left(-\frac{t}{t_{c 0}}\right)\right)+c_{0} \exp \left(-\frac{t}{t_{c 0}}\right)
$$

where $t_{c 0}$ is a characteristic time defined by:

$$
t_{c 0}=\frac{V}{Q_{\text {out }}}
$$

It is also the mean time for a solute particle to be in the system. Fig. 3 illustrates equation (5). The concentration increases from $c_{0}$ to $c_{\infty}$ asymptotically. The rate of this increase is given by the characteristic time being the time, at which the concentration is a fixed mixing ratio between $c_{0}$ and $c_{\infty}$ :

$$
c\left(t_{c 0}\right)=(1-\exp (-1)) c_{\infty}+\exp (-1) c_{0} \approx 0.63 c_{\infty}+0.37 c_{0}
$$


Equation (5) shows that the system can be described by only three parameters, the initial concentration, $c_{0}$, the steady state concentration, $c_{\infty}$, and the characteristic time, $t_{c 0}$. If we make an additional assumption that the concentration in the infiltrating water is negligible $\left(c_{p}=0\right)$, we can see from equation (4) that the relation between the steady state concentration and the concentration of the inflowing groundwater equals that of the rate of inflowing and outflowing groundwater $\left(c_{\infty} / c_{\text {in }}=Q_{\text {in }} / Q_{\text {out }}\right)$.

We can now apply this to the sabkha of Oum El Khialate. The various terms of equation (1) were obtained from a modeling study of the groundwater flow (ERI, 2010) and are given in Table 1. The surface area, $S$ is $52 \mathrm{~km}^{2}$, the aquifer thickness, $b$, is $6.7 \mathrm{~m}$ and the porosity, $\phi$, is 0.4 . This gives a characteristic time of almost 25000 years. If the concentration in the infiltrating water is neglected the steady state concentration will increase with a factor of 3.33 with respect to the concentration of the inflowing groundwater $\left(c_{o d} / c_{i n}=Q_{i n} / Q_{\text {out }}=3.33\right)$.

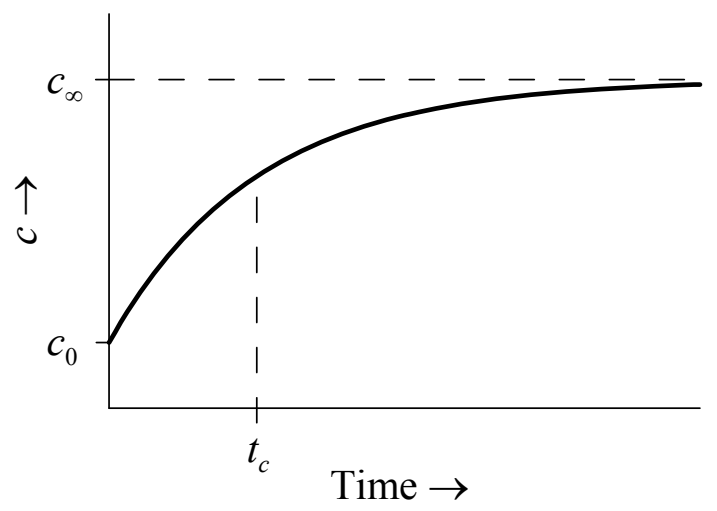

Fig. 3. Solution of the conservative ideally mixed model.

Table 1 The different components of the water balance (ERI, 2010). Flow rates are both given in volume per unit of time (second column) and volume per unit of horizontal surface per unit of time (third column)

\begin{tabular}{lrr}
\hline & $\mathrm{m}^{3} / \mathrm{s}$ & $\mathrm{mm} /$ year \\
\hline$Q_{p}$ & 0.020970 & 12.717 \\
$Q_{e}$ & 0.021380 & 12.966 \\
$Q_{\text {in }}$ & 0.000589 & 0.357 \\
$Q_{\text {out }}$ & 0.000177 & 0.107 \\
\hline
\end{tabular}

\subsection{One-dimensional advection model}

We assume steady state flow and transient conservative advective transport (no dispersion) in a one-dimensional aquifer and a constant upward flux from a deeper aquifer (Fig. 4). The flow equation is:

$$
\frac{d q}{d x}=\frac{P+G-E}{b}
$$

Where $q$ is the Darcy flux, $P$ is the infiltration, $E$ is the evaporation, $G$ is upward groundwater flow from the deeper aquifer (all in volume of water per surface per unit of 
time) and $b$ is aquifer thickness. The evaporation exceeds the infiltration plus the upward groundwater flow $(E>P+G)$.

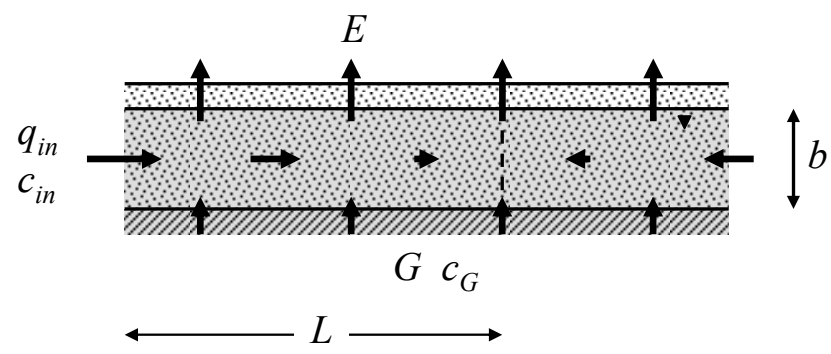

Fig. 4. Conceptual model of input and output flows in hydrologically system.

Boundary conditions are a prescribed Darcy flux, $q_{i n}$, at $x=0$. Solution of this equation is:

$$
q=q_{i n}+\frac{P+G-E}{b} x
$$

If we define a characteristic length, $L$, as the distance where $q=0$,

$$
L=q_{\text {in }} \frac{-b}{P+G-E}
$$

We can rewrite equation (9) as:

$$
q=\frac{P+G-E}{b}(x-L)
$$

Note that equation (9) or (11) simply describes a linear drop of the Darcy flux. For distance larger than $L$, the Darcy flux becomes negative, meaning a flow from right to left. So the distance $L$ also represents a watershed. If one wants to set a boundary condition at the right with a prescribed outward Darcy flux, $q_{\text {out }}$, one can simply calculate the distance, $L^{*}$, of this boundary from $q_{\text {out }}$ through equation (11):

$$
L^{*}=L+\frac{q_{\text {out }} b}{P+G-E}
$$

The transport equation is:

$$
\phi \frac{\partial c}{\partial t}+\frac{\partial q c}{\partial x}=\frac{P c_{P}+G c_{G}}{b}
$$

Where $\phi$ is porosity and $c_{G}$ and $c_{P}$ are the concentration in the deeper aquifer and infiltration water, respectively. Boundary conditions are a prescribed concentration, $c_{i n}$, at $x=0$. Initial concentration is $c_{0}$ for $x>0$.

The solution is (see the appendix for its derivation): 


$$
\begin{array}{ll}
c=\exp \left(\frac{t}{t_{c 1}}\right)\left(c_{0}+c_{a}\right)-c_{a} & \text { for } \mathrm{x} \geq L\left(1-\exp \left(\frac{-t}{t_{c 1}}\right)\right) \\
c=\frac{L}{L-x} c_{i n}+\frac{x}{L-x} c_{a} & \text { for } \mathrm{x}<L\left(1-\exp \left(\frac{-t}{t_{c 1}}\right)\right)
\end{array}
$$

Where $c_{a}$ is an average concentration in the infiltrating, upward flowing and evaporating water (the concentration of the last being zero):

$$
c_{a}=-\frac{P c_{P}+G c_{G}}{P+G-E}
$$

and where $t_{c 1}$ is a characteristic time defined by:

$$
t_{c 1}=\frac{-\phi b}{P+G-E}
$$

This characteristic time is the time for a solute to move from $x=0$ to $x=L(1-\exp (-1))$ $\approx 0.63 L$.

Fig. 5 shows equation (14) graphically. A front is moving towards the left. After this front the concentration is not affected yet by the inflowing water from the left boundary and increases only due to evaporation and solute input from infiltrating and upward flowing water. Before the front the concentration grows with distance but does not change in time. Note that the front moves slower when it is closer to the watershed. When time tends to infinite, the system reaches a steady state situation where the concentrations increases from the concentration of left boundary, $c_{i n}$, to infinity at the water shed where the Darcy flux equals zero. From the data from table 1 and assuming no upward flux, a porosity, $\phi$, of 0.4 an aquifer thickness, $b$, of $6.7 \mathrm{~m}$, we can calculate, that the characteristic time, $t_{c 1}$, for the sabkha of Oum El Khialate is about 11000 years.

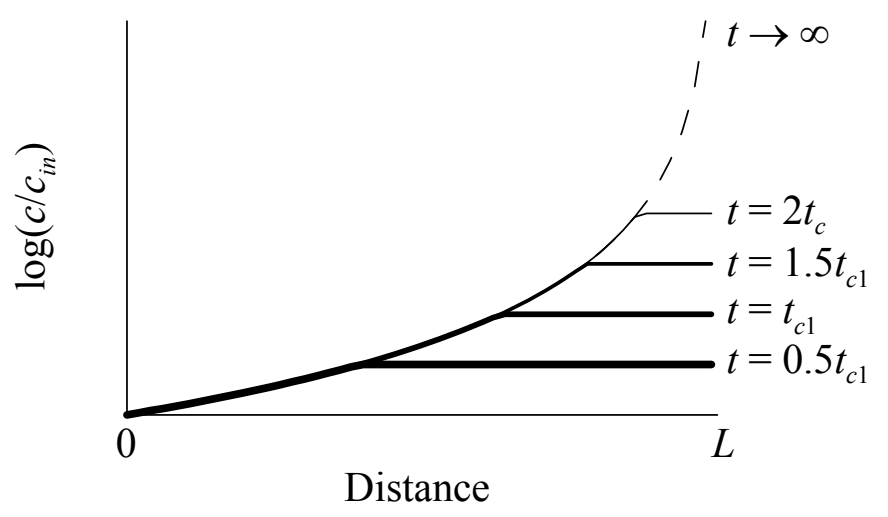

Fig. 5. Solution of the conservative 1D advection model. In this graph the initial concentration, $c_{0}$, equals the prescribed concentration at the left boundary, $c_{i n}$. 


\section{Numerical reactive transport models}

We used the code PROOST to carry out the numerical simulations (Slooten et al., 2010). PROOST is a general purpose hydrological modeling tool that can solve a large variety of conservation equations expressed as partial differential equations. It was programed following the object oriented (OO) paradigm in FORTRAN 95. All geochemical processes are included by coupling PROOST to the code CHEPROO (Bea et al., 2009; Gamazo et al., 2012). CHEPROO is an OO tool specialized in complex geochemical processes. This code has been used for other high salinity reactive transport models (Gamazo et al., 2011; Gamazo et al., 2013).

\subsection{One-dimensional models}

We built three one-dimensional models. They differ from each other by the hydrological boundary conditions and/or the chemical composition of the inflowing waters.

\subsubsection{Model with fresh water at the boundary and without upward flow}

We first developed a horizontal one-dimensional numerical model that considers advection, dispersion, evaporation and precipitation and dissolution of salt minerals. Its length is $5000 \mathrm{~m}$ and it is discretized using finite elements with lengths ranging from $100 \mathrm{~m}$ at the left boundary to $50 \mathrm{~m}$ at the right. No upward groundwater from the bottom is considered. Evaporation minus infiltration is assumed to occur over the whole length of the system and is calculated as a function of the water activity of the sabkha and the relative humidity of the atmosphere:

$$
E-P=\alpha\left(P_{\text {vap }, \text { out }}-P_{\text {vap }}\right)
$$

where $E$ and $P$ are the rate of evaporation and infiltration respectively, $p_{\text {vap,out }}$ is the external vapor pressure $\left(2.06 \cdot 10^{-3} \mathrm{MPa}\right.$ which correspond to a relative humidity of 0.65 at $25^{\circ} \mathrm{C}$ ), $p_{\text {vap }}$ is the vapor pressure in equilibrium with the aquifer (which depends on water activity) and $\alpha$ an exchange coefficient. For $\alpha$ we used a value of $4.04 \cdot 10^{-4}$ $\mathrm{mol}_{\text {water }} / \mathrm{m}^{2} / \mathrm{seconds} / \mathrm{MPa}$, which corresponds to an evaporation minus infiltration of $0.25 \mathrm{~mm}$ year $^{-1}$ when the water activity of the sabkha equals 1 . The head at the left boundary was fixed, whereas the right boundary was closed for both water and solute. As the storage terms for liquid water can be neglected the water flowing at the left boundary is almost identical to the total evaporation in the system (independent of the permeability and the value of the prescribed head at the left). For each chemical component a prescribed solute flux at the left is assumed that equals the water flux at this boundary times a concentration. For this first model we used the total aqueous concentrations of fresh groundwater sampled to the west of the sabkha (water A of Table 2). For the initial concentrations of the aquifer we used the same values. We considered a porosity of 0.4 and a dispersivity of $100 \mathrm{~m}$.

The minerals that can precipitate and dissolve are listed in Table 3. We also assume that the water of the sabkha is in equilibrium with an atmospheric $\mathrm{CO}_{2}$ pressure of $10^{-3.5} \mathrm{bar}$. We take into account the effect of precipitation or dissolution of hydrated minerals on the mass balance of water, proposed by Gamazo et al. (2012). The activity coefficients of the aqueous species, including that of water, were computed using the Pitzer (1973) ion-ion interaction model with the parameters given by Harvie et al. (1984). 
Table 2 Chemical composition of inflowing and initial water. A: Fresh water from the West of the sabkha; B: Saline water from the limit of the sabkha: C Water from the aquifer beneath the sabkha.

\begin{tabular}{llrrr}
\hline & & \multicolumn{1}{c}{$\mathrm{A}$} & $\mathrm{B}$ & $\mathrm{C}$ \\
\hline $\mathrm{pH}$ & & 8.33 & 8.25 & 6.89 \\
Total & $\mathrm{Na}$ & $1.21 \cdot 10^{-2}$ & $5.50 \cdot 10^{-1}$ & $2.64 \cdot 10^{-1}$ \\
aqueous & $\mathrm{Ca}$ & $5.97 \cdot 10^{-3}$ & $5.37 \cdot 10^{-3}$ & $1.91 \cdot 10^{-2}$ \\
concentration & $\mathrm{SO}_{4}$ & $9.52 \cdot 10^{-3}$ & $1.99 \cdot 10^{-1}$ & $1.86 \cdot 10^{-2}$ \\
$\left(\mathrm{~mol} \mathrm{~kg}_{\mathrm{w}}{ }^{-1}\right)$ & $\mathrm{Cl}$ & $7.23 \cdot 10^{-3}$ & $2.96 \cdot 10^{-1}$ & $2.97 \cdot 10^{-1}$ \\
& $\mathrm{HCO}_{3}$ & $2.21 \cdot 10^{-4}$ & $2.93 \cdot 10^{-4}$ & $2.01 \cdot 10^{-3}$ \\
& $\mathrm{Mg}$ & $2.98 \cdot 10^{-3}$ & $6.69 \cdot 10^{-2}$ & $1.69 \cdot 10^{-2}$ \\
Saturation & anhydrite & -0.72 & -0.58 & -0.57 \\
index & bischofite & -11.82 & -8.00 & -8.24 \\
& bloedite & -9.44 & -4.12 & -6.68 \\
& calcite & 0.00 & -0.72 & -0.37 \\
& dolomite & 0.00 & 0.00 & -0.49 \\
& epsomite & -3.47 & -1.94 & -3.11 \\
& glauberite & -6.26 & -2.36 & -3.73 \\
& gypsum & -0.50 & -0.37 & -0.36 \\
& halite & -5.80 & -2.78 & -3.00 \\
& hexahydrite & -3.72 & -2.18 & -3.35 \\
& kieserite & -5.23 & -3.65 & -4.84 \\
& magnesite & -0.84 & -0.12 & -0.97 \\
& mirabilite & -5.22 & -1.53 & -2.88 \\
& pentahydrite & -4.07 & -2.52 & -3.69 \\
$\mathrm{CO}_{2}$ partial pressure (bar) & -3.50 & -3.50 & -1.26 \\
\hline
\end{tabular}

Table 3 Minerals taken into account by the numerical reactive transport model

\begin{tabular}{|c|c|}
\hline Mineral & Formula \\
\hline Anhydrite & $\mathrm{CaSO}_{4}$ \\
\hline Bischofite & $\mathrm{MgCl}_{2} \cdot 6 \mathrm{H}_{2} \mathrm{O}$ \\
\hline Bloedite & $\mathrm{Na}_{2} \mathrm{Mg}(\mathrm{SO} 4)_{2} \cdot 4 \mathrm{H}_{2} \mathrm{O}$ \\
\hline Calcite & $\mathrm{CaCO}_{3}$ \\
\hline Dolomite & $\mathrm{CaMg}\left(\mathrm{CO}_{3}\right)_{2}$ \\
\hline Epsomite & $\mathrm{MgSO}_{4} \cdot 7 \mathrm{H}_{2} \mathrm{O}$ \\
\hline Glauberite & $\mathrm{Na}_{2} \mathrm{Ca}\left(\mathrm{SO}_{4}\right)_{2}$ \\
\hline Gypsum & $\mathrm{CaSO}_{4} \cdot 2 \mathrm{H}_{2} \mathrm{O}$ \\
\hline Halite & $\mathrm{NaCl}$ \\
\hline Hexahydrite & $\mathrm{MgSO}_{4} \cdot 6 \mathrm{H}_{2} \mathrm{O}$ \\
\hline Kieserite & $\mathrm{MgSO}_{4} \cdot \mathrm{H}_{2} \mathrm{O}$ \\
\hline Magnesite & $\mathrm{MgCO}_{3}$ \\
\hline Mirabilite & $\mathrm{Na}_{2} \mathrm{SO}_{4} \cdot 10 \mathrm{H}_{2} \mathrm{O}$ \\
\hline Sylvite & $\mathrm{KCl}$ \\
\hline
\end{tabular}



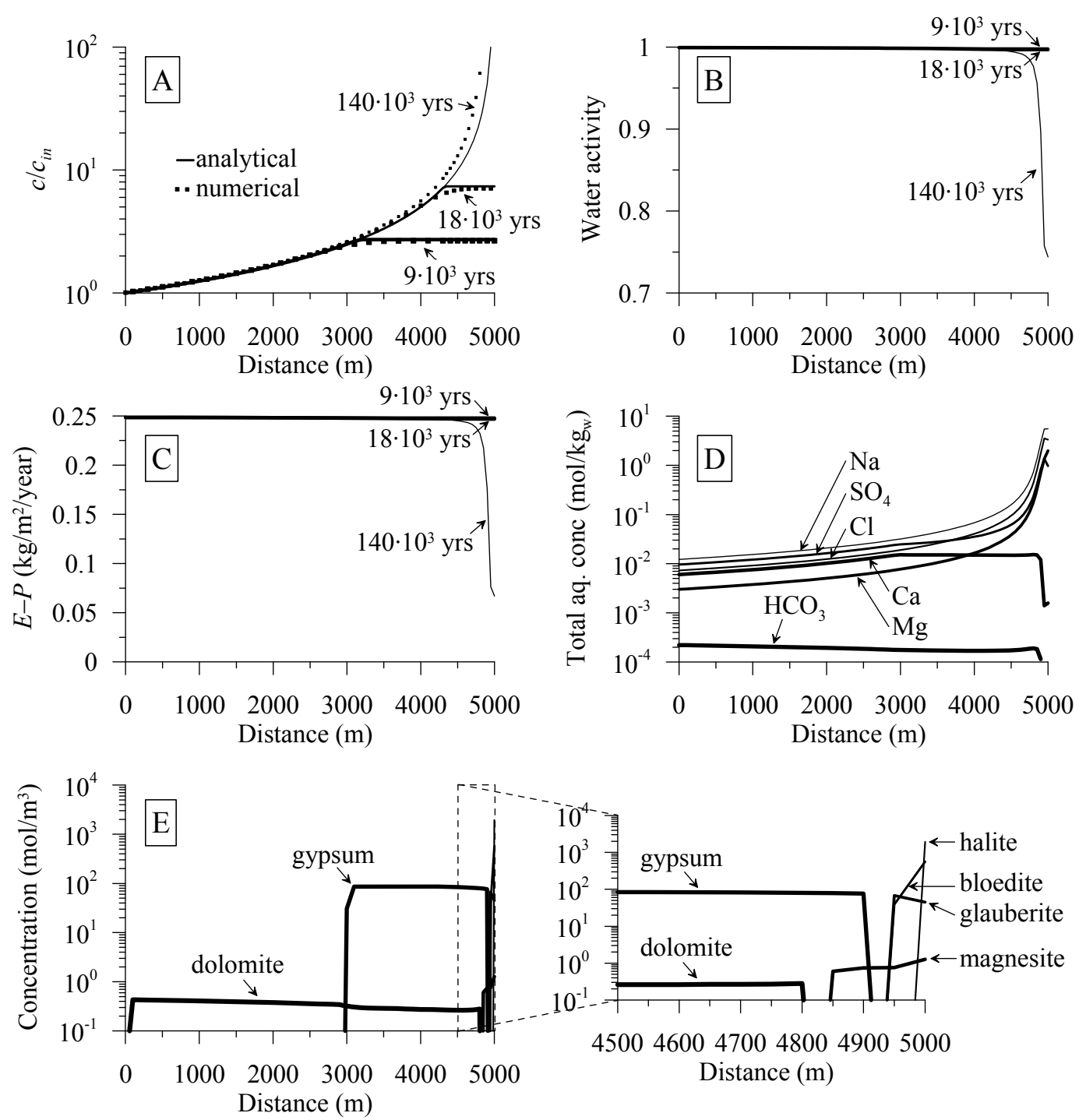

Figure 6. Results of the first $1 \mathrm{D}$ model after 140000 years without water flowing upwards from a lower aquifer and using the chemistry of the fresh water (A, table 4) for the left boundary. A: adimensional concentration of a conservative specie, the numerical model (dots) is compared with the analytical model of equation 14 (lines). B: Water activity. C: Evaporation minus infiltration $(E-P)$. D Total aqueous concentrations of the components after $140 \cdot 103$ years. E: Concentration of minerals after $140 \cdot 10^{3}$ years with an amplification of the last $500 \mathrm{~m}$.

Fig. 6 shows the results of the conservative tracer, the water activity, the evaporation minus infiltration, concentrations of aqueous components and concentrations of minerals versus time after 140000 years. This is about thirteen times the characteristic time calculated in section 3.2 and practically reflects a steady state situation. The concentrations of dissolved species (Fig. 6D) increase from left to right and, hence, water activity (Fig. 6B) and evaporation minus infiltration (Fig. 6C) decreases. The concentrations of the conservative tracer are very similar to those of the analytical model (Fig. 6A). Only near the watershed and after 14000 years a difference between analytical and numerical model can be noticed. This can be explained by the fact that the analytical model assumes a constant evaporation minus infiltration of $0.25 \mathrm{~mm} / \mathrm{year}$ 
contrary to the numerical model. The precipitation of the minerals show a clear sequence (Fig 6E). The first mineral to precipitate, besides dolomite which is already present, is gypsum, followed by magnesite, glauberite, bloedite and halite. Most minerals only precipitate at the last $50 \mathrm{~m}$ with the exception of gypsum precipitating at the last $2000 \mathrm{~m}$ of the system. This precipitation of minerals does not correspond to what is observed in reality, where mirabilite also precipitates at the center of the sabkha.

\subsubsection{Model with saline water at the boundary and without upward flow}

In order to increase the mirabilite precipitation zone on the model we developed a second model. For this model the concentrations measured at the limit of the sabkha (water B, Table 2) was used for chemical composition of the inflowing water at the left boundary as well as of the initial water.

Results are shown in Fig. 7. As the inflowing water has a higher salinity, precipitation of the minerals begins at a shorter distance from the left boundary than for the first model. Also water activity together with evaporation minus infiltration drops at shorter distance. As the zone of lower evaporation minus infiltration extends the mismatch between the analytical and numerical model increases. The sequence of precipitating minerals is roughly the same as the first model with the exception of the sulphate sodium minerals (mirabilite). The first mineral to precipitate is gypsum, followed by magnesite, glauberite, bloedite (in stead of epsomite in the first model), halite and mirabilite. Interestingly, the water activity has a constant value at the last $800 \mathrm{~m}$ of the sabkha. This can be explained by means of the phase rule. In this part of the sabkha the number of chemical components $\left(7: \mathrm{Ca}, \mathrm{Cl}, \mathrm{H}, \mathrm{HCO}_{3}, \mathrm{Mg}, \mathrm{Na}\right.$, and $\mathrm{SO}_{4}$ ) equals the number of phases (6: magnesite, glauberite, bloedite, halite and mirabilite, and $\mathrm{CO}_{2}(\mathrm{~g})$ ) plus a constraint on charge balance, thus, fixing the chemical composition as well as the water activity.

\subsubsection{Model with saline water at the boundary and with upward flow}

Another hypothesis we considered was the occurrence of a upward water flow from a lower aquifer that mixes with water in the sabkha. Therefore, we made a third model that adds a water flux of $0.0752 \mathrm{~mm} /$ year over the whole length of the system. The same chemical composition as for the second model (water B, Table 2) was considered for the inflowing water at the left boundary and initial water. We used the chemistry of aquifers beneath the sabkha (water $\mathrm{C}$, Table 2) for the upward flowing water.

Results are shown in Fig. 8. The concentrations of precipitated minerals differ from those of the second model, but the sequence is the same with the exception that mirabilite precipitates at a longer distance from the left boundary. This result reflects better the observations made at the site. 

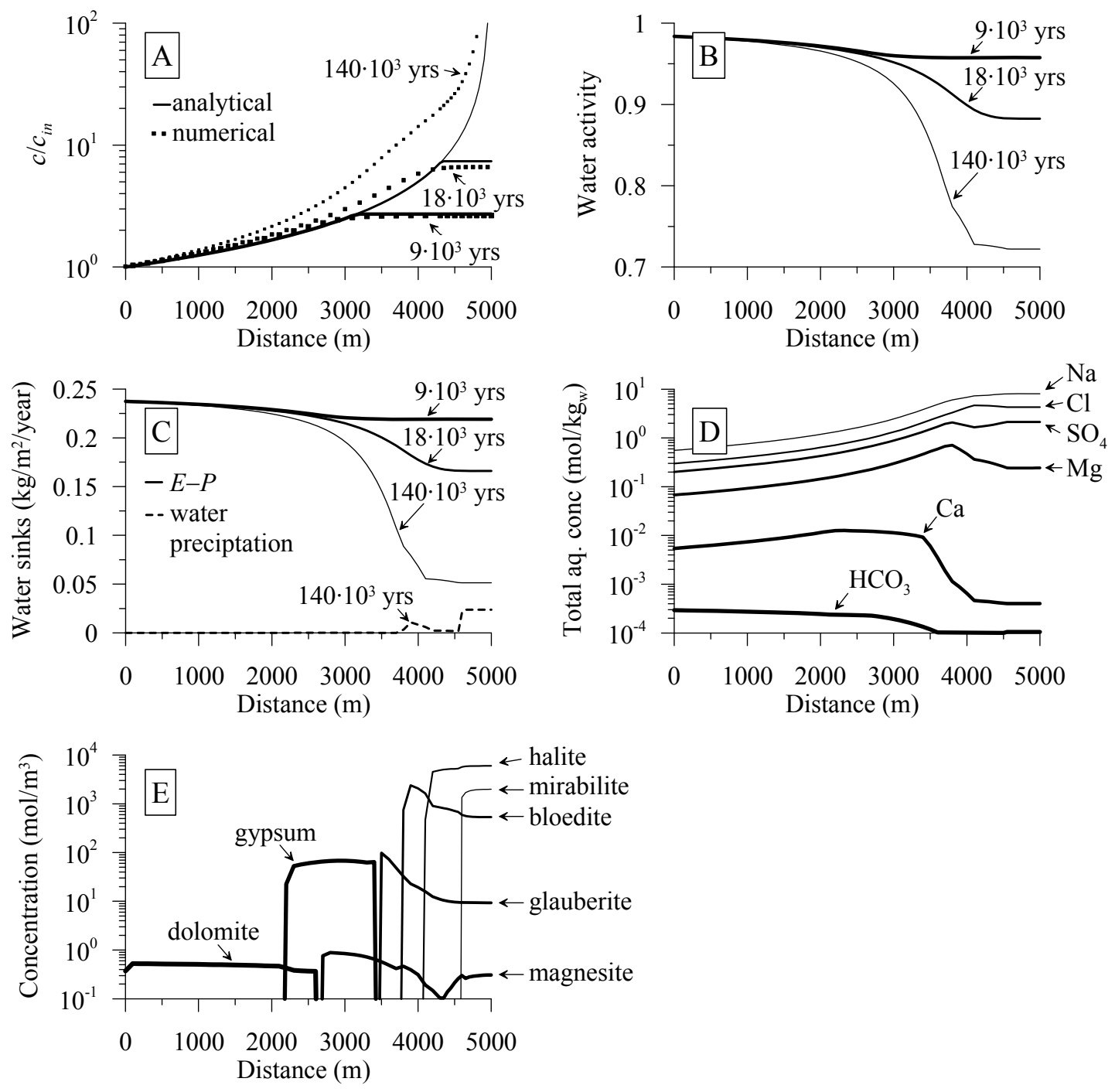

Figure 7. Results of the second 1D model after 140000 years without water flowing upwards from a lower aquifer and using the water from the limit of the sabkha $(\mathrm{B}$, table 4) for the left boundary. A: adimensional concentration of a conservative specie, the numerical model (dots) is compared with the analytical model of equation 14 (lines). B: Water activity. C: Water sinks including evaporation minus infiltration $(E-P)$ and water that is precipitating in hydrated minerals. D Total aqueous concentrations of the components after $140 \cdot 10^{3}$ years. E: Concentration of minerals after $140 \cdot 10^{3}$ years. 

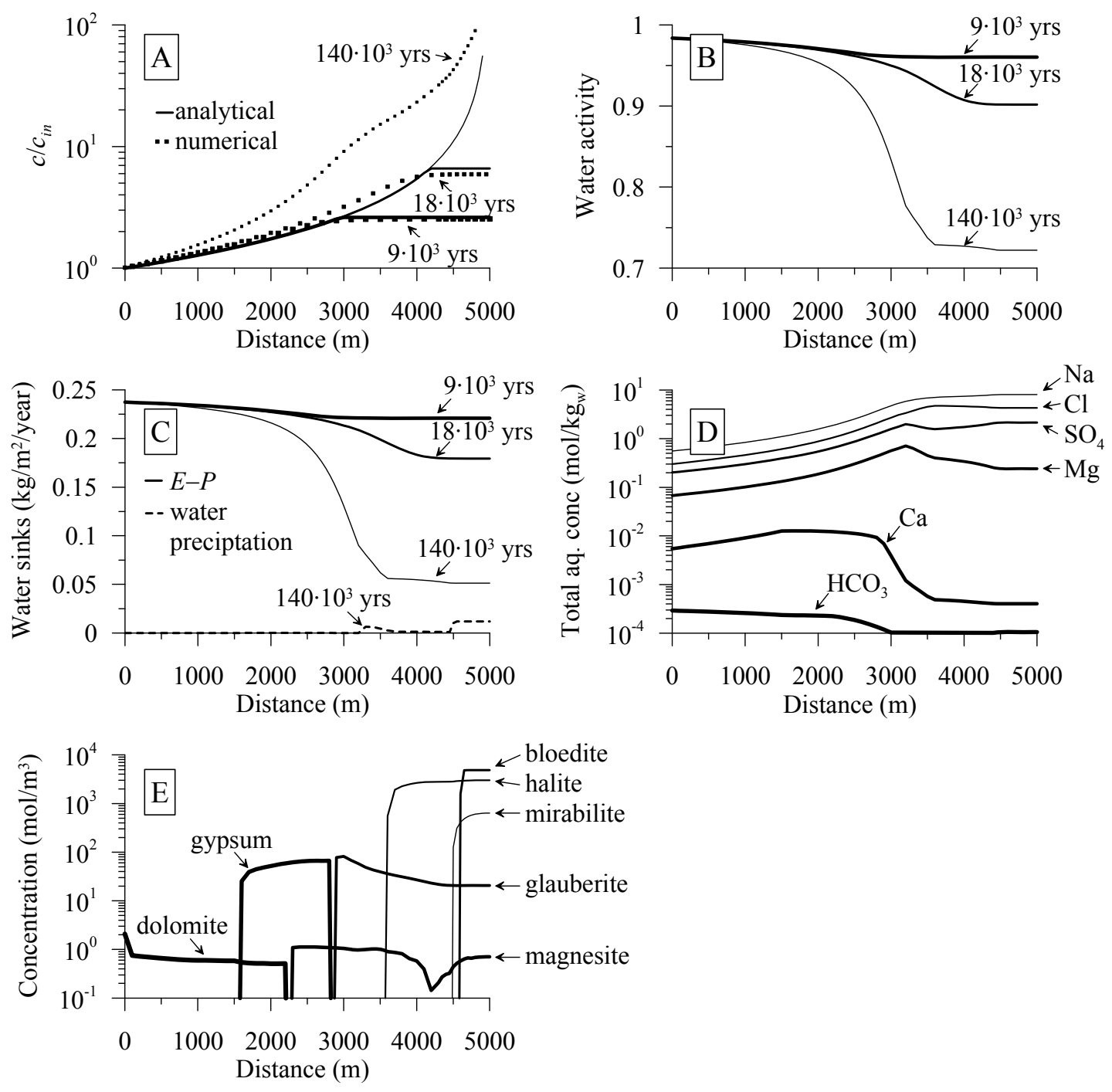

Figure 8. Results of the third 1D model after 140000 years with water flowing upwards from a lower aquifer and using the chemistry of water from the limit of the sabkha (B, table 4) for the left boundary and using that of water $\mathrm{C}$ (table 4) for the up-flowing water. A: adimensional concentration of a conservative specie, the numerical model (dots) is compared with the analytical model of equation 14 (lines). B: Water activity. $\mathrm{C}$ : Water sinks including evaporation minus infiltration $(\mathrm{E}-\mathrm{P})$ and water that is precipitating in hydrated minerals. D Total aqueous concentrations of the components after $140 \cdot 10^{3}$ years. E: Concentration of minerals after $140 \cdot 10^{3}$ years.

\subsection{Two-dimensional model}

In order to study the vertical distribution of concentrations of aqueous and mineral species we consider a two-dimensional vertical model. We used a grid of triangular elements with heights of $0.57 \mathrm{~m}$ (that is, one tenth of the thickness of the sabkha) and lengths ranging from $100 \mathrm{~m}$ at the left boundary to $50 \mathrm{~m}$ at the right (the same as for the one-dimensional models). We used a longitudinal dispersivity of $100 \mathrm{~m}$, a transversal dispersivity of $10 \mathrm{~m}$ and a porosity of 0.4 . The boundary conditions are the same as the previous 1D model of section 4.1.3. For reasons of computational time the simulated time was reduced to 11000 years. 
The results of the aqueous species (not shown) are practically the same as for the onedimensional model with uniform concentrations in the vertical dimension. The reason is that the thickness of the sabkha $(5.7 \mathrm{~m})$ is of the same magnitude as the transversal dispersivity $(10 \mathrm{~m})$, which causes an almost complete vertical mixing. On the other hand, the concentrations of minerals do exhibit a vertical distribution. As illustrated in Fig. 9, precipitation only occurs at the top surface of the sabkha where the evaporation takes place. However, averaging the concentrations of the minerals over depth gives results very similar to the 1D model of section 4.1.3. In fact, an exact solution would give infinite concentrations of minerals at the surface, which has infinitesimal small thickness. However, in a grid of elements of finite size the upper row of nodes, that represent the surface, does not have an infinitesimal small thickness but a finite thickness equal to half the thickness of the upper row of elements. Thus the calculated values of minerals depend on the grid size and do not have a real meaning.

\section{D model}
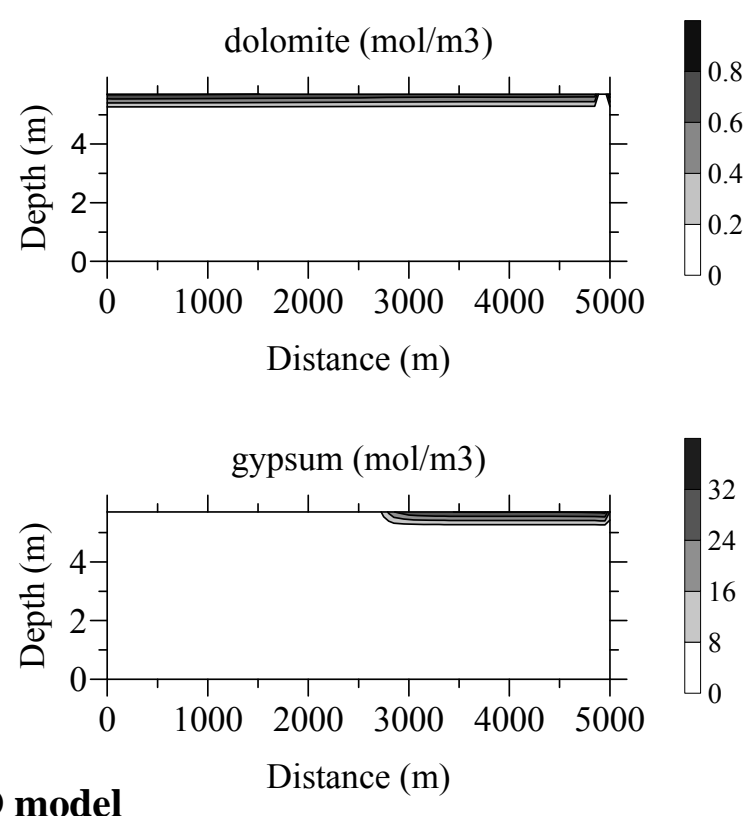

\section{D model}

Distance $(\mathrm{m})$

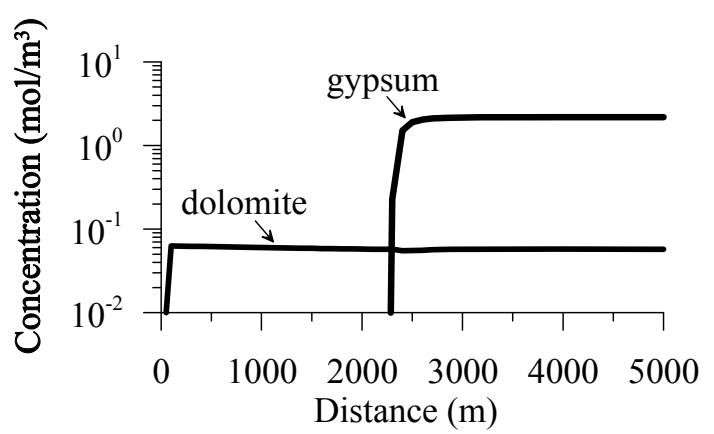

Fig. 9. Concentrations of minerals for the 2D model after 11000 years. The results are compared with the 1D model of section 4.1 .3 for the same time. 


\section{Conclusions and discussion}

We have studied the effect of evaporation and groundwater flow on the formation of salt minerals in the sabkha of Oum El Khialate in South East Tunisia, characterized by sulfate sodium deposits. As there are no important surface water bodies present in this sabkha, transport of solutes is dominated by advection and we cannot use the classical ideally mixed models of Sanford and Wood (1991) and Yechieli and Wood (2002). An analytical one-dimensional conservative model showed that salinity varies with distance and may become very high (actually it goes to infinity as there is no precipitation) near a water divide where the flux of water is zero.

We have also developed three numerical reactive transport models. All models showed roughly the same sequence of precipitating minerals. First dolomite precipitates then gypsum, magnesite, bloedite, epsomite, halite and mirabilite. However, the amount as well as the distribution of salt minerals precipitation depends on the chemical composition of the inflowing water and whether an upward flow from a deeper aquifer is assumed. A model which assumes inflowing water at the boundary with a low salinity and no upward flow predicts precipitation of the main minerals only at a small part of the sabkha near the water divide. When a higher salinity at the boundary or an upward flow was assumed, the region with precipitating minerals is larger, which reflects better observations made at the site. A vertical two-dimensional model showed no important differences with the one-dimensional model. It only revealed that minerals precipitate at the surface of the sabkha.

We admit that our reactive transport model is still rather simple and that there may be processes that could affect the formation of the sabhka, but have not been simulated in our models. The groundwater could be enriched in $\mathrm{Na}$ by cation exchange between $\mathrm{Na}$ and $\mathrm{Ca}$ from the clay of Mhira. Also the difference in salinity could give rise to density dependent flow. We don't believe that this is important in the sabkha itself, because due to the small thickness $(5.7 \mathrm{~m})$ vertical mixing is large enough to prevent the development of a vertical density gradient, at least for the dispersivities that we used (10 $\mathrm{m})$. However, the water of the sabkha could be more saline and, consequently, denser than the water at deeper aquifers causing a downward flow rather than an upward flow. Nevertheless, the small differences between the second 1D model, that does not consider an upward flow, and the third model, that does, suggests that a downward flow will not have a big impact.

Finally, the patterns of groundwater flow, shown in Figure 2, reveal that a onedimensional model may be to simplistic and that a horizontal two-dimensional model is required for a more accurate calculation of mineral distribution. This would also permit a more precise comparison between modeled and observed distribution of precipitated minerals. Further research is needed to address these issues.

\section{Appendix}

To solve the transport equation (13) we define a front moving with the water in a Lagrangian fashion. The velocity of this front $(d x / d t)$ is given by: 


$$
\phi \frac{d x}{d t}=q
$$

If at time $t=0$ the front is at $x=0$ and by using equation (11), we can calculate the position of the front, $x$, as a function of time:

$$
\begin{aligned}
\phi \frac{d x}{d t} & =\frac{P+E-G}{b}(L-x) \Rightarrow d \ln (L-x)=-d\left(\frac{P+E-G}{\phi b} t\right) \\
& \Rightarrow \ln \left(\frac{L-x}{L}\right)=-\frac{P+E-G}{\phi b} t \\
& \Rightarrow x=L\left(1-\exp \left(\frac{-(P+E-G)}{\phi b} t\right)\right)
\end{aligned}
$$

If we define a characteristic time, $t_{c 1}$, as

$$
t_{c 1}=\frac{-\phi b}{P+G-E}
$$

we can rewrite (A2) as

$$
x=L\left(1-\exp \left(\frac{-t}{t_{c 1}}\right)\right)
$$

The concentration at this moving front can be written as:

$$
\begin{aligned}
\phi \frac{d c(x(t), t)}{d t} & =\phi \frac{\partial c}{\partial t}+\phi \frac{\partial c}{\partial x} \frac{d x}{d t} \\
& =\phi \frac{\partial c}{\partial t}+q \frac{\partial c}{\partial x}
\end{aligned}
$$

The transport equation (13) can be rewritten as:

$$
\begin{aligned}
& \phi \frac{\partial c}{\partial t}+\frac{\partial q c}{\partial x}=\frac{P c_{P}+G c_{G}}{b} \\
& \Rightarrow \phi \frac{\partial c}{\partial t}+q \frac{\partial c}{\partial x}=\frac{P c_{P}+G c_{G}}{b}-c \frac{\partial q}{\partial x}
\end{aligned}
$$

Substitution of equation (A6) into (A5) gives:

$$
\begin{aligned}
\phi \frac{d c}{d t} & =\frac{P c_{P}+G c_{G}}{b}-c \frac{\partial q}{\partial x} \\
& =\frac{P c_{P}+G c_{G}}{b}+\frac{E-P-G}{b} c \\
& \Rightarrow \ln \left(c+\frac{P c_{P}+G c_{G}}{E-P-G}\right)=\frac{t}{t_{c 1}}+k
\end{aligned}
$$


where $k$ is an integration constant which we can calculate from initial or boundary conditions. By defining $c_{a}$ as the average concentration in the infiltrating, upward flowing and evaporating water (the concentration of the last being zero):

$$
c_{a}=\frac{P c_{P}+G c_{G}}{E-P-G}
$$

we can rewrite (A7) as:

$$
\ln \left(c+c_{a}\right)=\frac{t}{t_{c 1}}+k
$$

By using equation (A4) we can also write:

$$
\ln \left(c+c_{a}\right)=-\ln \left(\frac{L-x}{L}\right)+k
$$

For times larger than the time for the front to travel from $x=0$ to $x$ that is, according to equation (A4), for times:

$$
t \geq-t_{c 1} \ln \left(\frac{L-x}{L}\right)
$$

or for distances:

$$
x \geq L\left(1-\exp \left(\frac{-t}{t_{c 1}}\right)\right)
$$

we must apply the initial condition, $c=c_{0}$ at $t=0$, to equation (A9), yielding:

$$
\begin{aligned}
& k=\ln \left(c_{0}+c_{a}\right) \\
& \Rightarrow c=\exp \left(\frac{t}{t_{c 1}}\right)\left(c_{0}+c_{a}\right)-c_{a} \quad \text { for } x \geq L\left(1-\exp \left(\frac{-t}{t_{c 1}}\right)\right)
\end{aligned}
$$

For times smaller than the time for the front to travel from $x=0$ to $x$, that is, according to equation (A4), for times

$$
t<-t_{c 1} \ln \left(\frac{L-x}{L}\right)
$$

or for distances:

$$
x<L\left(1-\exp \left(\frac{-t}{t_{c 1}}\right)\right)
$$

we must apply the boundary condition, $c=c_{i n}$ at $x=0$, to equation (A10), yielding: 


$$
\begin{aligned}
& k=\ln \left(c_{i n}+c_{a}\right) \\
& \Rightarrow c=\frac{L}{L-x} c_{i n}+\frac{x}{L-x} c_{a} \quad \text { for } x<L\left(1-\exp \left(\frac{-t}{t_{c 1}}\right)\right)
\end{aligned}
$$

\section{Acknowledgements}

This study is part of a doctoral scholarship that was funded by the High Ministry of Education and the Laboratory of Modeling in Hydraulic and Environment in National School of Engineering of Tunis. The authors would like to thank you the Editor and the Reviewers for their constructive comments.

\section{References}

Appelo, C.A.J., Rolle, M. 2010. PHT3D: A Reactive Multicomponent Transport Model for Saturated Porous Media. Ground Water. doi: 10.1111/j.1745-6584.2010.00732.x

Audigane, P., Gaus, I., Czernichowski-Lauriol, I., Pruess, K., Xu, T., 2007. Twodimensional reactive transport modeling of $\mathrm{CO}_{2}$ injection in a saline aquifer at the Sleipner site. Am. J. Sci. 307, 974-1008 DOI: 10.2475/07.2007.02

Ayora, C., Cendon, D.I., Taberner, C., Pueyo, J.J., 2001. Brine-mineral reactions in evaporite basins: Implications for the composition of ancient oceans. Geology. 29, 251254.

Baccar, L., Louhaichi, M.A., 2007. Hydrogeological survey of Sebkhet Oum El Khialat for the evaluation of the mining stock of $\mathrm{Na}_{2} \mathrm{SO}_{4}$. Final Report. ERI

Bea, S.A., Carrera, J., Ayora, C., Batlle, F., Saaltink, M.W., 2009. CHEPROO: A Fortran 90 object-oriented module to solve chemical processes in Earth Science models. Computers \& Geosciences 35 (6), 1098-1112.

Bea, S.A., Ayora, C., Carrera, J., Saaltink, M.W., Bold, B. 2010. Geochemical and environmental controls on the genesis of soluble efflorescent salts in Coastal Mine Tailings Deposits: A discussion based on reactive transport Modeling. J. Contaminant Hydrol. 111, 65-82

Bouhlila, R., 1999. Ecoulements, Transports et Réactions Géochimiques Couplés dans le milieu poreux. Thèse de doctorat d'état ès sciences. ENIT.

Dalkhaa C., Shevalier M., Nightingale, M., Mayer B., 2013. 2-D reactive transport modeling of the fate of $\mathrm{CO} 2$ injected into a saline aquifer in the Wabamun Lake Area, Alberta, Canada. Applied Geochemistry 38, 10-23

Dotsika E., Poutoukis, D., Tzavidopoulos, I., Maniatis, Y., Ignatiadou, D., Raco, B., 2009. A natron source at Pikrolimni Lake in Greece? Geochemical evidence. J. Geochemical Exploration 103: 133-143. 
ERI (Eco-Ressources International) 2010. Modélisation de la nappe de saumures de Sebkhat Oum Lekhaliette et de son mode d'exploitation. Rapport interne.

Eugster, H.P., 1980. Geochemistry of evaporitic lacustrine deposits. Ann. Rev. EarthPlanet. Sci. 8, 35-63.

Eugster, H.P., Jones, B.F., 1979. Behavior of major solutes during closed-basin brine evolution. American J. Sci. 279:609-631.

Gamazo, P., S.A. Bea, M.W. Saaltink, J. Carrera, C. Ayora 2011. Modeling the interaction between evaporation and chemical composition in a natural saline system, $\mathrm{J}$. Hydrol., 401, 154-164, doi: 10.1016/j.jhydrol.2011.02.018.

Gamazo, P., Saaltink, M.W., Carrera, J., Slooten, L., Bea, S.A., 2012. A consistent compositional formulation for multiphase reactive transport where chemistry affects hydrodynamics. Adv. Water Resour. 35, 83-93.

Gamazo, P., M.W. Saaltink, J. Carrera, L. Slooten, S.A. Bea, M. Gran 2013. Modeling the influence of $\mathrm{MgSO} 4$ invariant points on multiphase reactive transport process during saline soil evaporation, Physics and Chemistry of the Earth, 64, 57-64, doi: 10.1016/j.pce.2013.02.001.

Garcia-Veigas, J., Rosell, L., Orti, F., Gundogan, I., Helvaci, C., 2011. Mineralogy, diagenesis and hydrochemical evolution in a probertite-glauberite-halite saline lake (Miocene, Emet Basin, Turkey). Chemical Geology 280, 352-364

Gomis, V., Boluda, N., Ruiz, F., 1995. Application of a model for simulating transport of reactive multispecies components to the study of the hydrochemistry of salt water intrusions. J. Contaminant Hydrol. 22, 67-81

Guizani, Zarai, 2009. Synthèse des travaux de prospection de $\mathrm{Na}_{2} \mathrm{SO}_{4}$. ERI.

Harvie, C.E., Moller, N., Weare, J.H., 1984. The prediction of mineral solubilities in natural waters: The Na-K-Mg-CaH-Cl-SO $-\mathrm{OH}-\mathrm{HCO}_{3}-\mathrm{CO}_{3}-\mathrm{CO}_{2}-\mathrm{H}_{2} \mathrm{O}$ system to high ionic strength at $25^{\circ} \mathrm{C}$. Geochimica et Cosmochimica Acta, 48,723-751.

Ingebritsen, S.E., Sanford, W.E., Neuzil C., 1998. Evaporites. Groundwater in Geologic Processes. Cambridge Univ. Press. pp. 245-267.

Khalili, M., Torabi, H., 2003. The exploration of sodium-sulphate in Aran playa, Kashan, central Iran. Carbonates and Evaporites, v. 18, no. 2,120-124.

Keating, E.H., and J.M. Bahr, 1998. Reactive transport modeling of redox geochemistry: Approaches to chemical disequilibrium and reaction rate estimation at a site in northern Wisconsin. Water Resour. Res. 35, 3573-3584.

Kelly, I.L., Holmden, C., 2001. Reconnaissance hydrogeochemistry of economic deposits of sodium sulfate (mirabilite) in saline lakes, Saskatchewan, Canada. Hydrobiologia 466: 279-289.

Last, W.M. 1992. Chemical composition of saline and subsaline lakes of the northern Great Plains, western Canada. Int. J. Salt Lake Res. 1(2), 47-76. 
Last, W. M. 1989. Continental brines and evaporites of the northern Great Plains of Canada. Sedimentary Geology, 64: 207-221.

Last, M.W., 1984. Sedimentology of playa lakes of the northern Great Plains. Can. J.Earth Sci. 21. 107-125.

Last, M.W., Schweyen, T.H., 1983. Sedimentology and geochemistry of saline lakes of the Great Plains. Hydrobiologia 105:245-263.

Mao, X., Prommer, H., Barry, D.A., Langevin, C.D., Panteleit, B., Li, L., 2006. Threedimensional model for multi-component reactive transport with variable density groundwater flow. Environmental Modelling \& Software 21, 615-628.

Nield, D. A., Simmons, C. T., Kuznetsov, A. V., Ward, J. D. 2008 On the evolution of salt lakes: Episodic convection beneath an evaporating salt lake. Water Resour. Res. 44, W02439, doi:10.1029/2007WR006161.

Orti, F., Gundogan, I., Helvaci, C., 2002. Sodium sulphate deposits of Neogene age: theKirmir Formation, Beypazari Basin, Turkey. Sedimentary Geol. 146 : 305- 333.

Pitzer, K. S., 1973. Thermodynamics of electrolytes. 1. Theoretical basis and general equations, J. Phys. Chem., 77, 268-277.

Rahimpour-Bonab, H, Abdi, L., 2012. Sedimentology and origin of Meyghan lake/playa deposits in Sanandaj-Sirjan zone, Iran. Carbonates Evaporites, 27:375-393 DOI $10.1007 / \mathrm{s} 13146-012-0119-0$

Rodriguez-Rodrigueza, M., Benavente J., Cruz-San Julian, J.J., Moral Martosn F., 2006. Estimation of ground-water exchange with semi-arid playa lakes (Antequera region, southern Spain). J. Arid Envir. 66, 272-289

Rosen, M.R., 1994. The importance of groundwater in playas: a review of playa classifications and the sedimentology and hydrology of playas. Geol. Soc. Am., Spec. Paper 289, 1-18.

Sanford W.E., Wood W.W., 1991. Brine evolution and mineral deposition in hydrologically open evaporate basins. American J. Sci., 291, 687-710.

Slooten, L.J., Batlle, F., Carrera, J., 2010. An XML based problem solving environment for hydrological problems. XVIII Conference on Computational Methods in Water Resources CMWR (http://congress.cimne.com/cmwr2010).

Smith M., 2000. A Geochemical investigation of the Darling and Ysterfontein saline Pans, Western Cape, South Africa. Master of Science.

Steefel, C. I., DePaolo, D.J., Lichtner, P.C., 2005. Reactive transport modeling: An essential tool and a new research approach for the Earth sciences. Earth Planet Sci Lett 240:539-558.

Valero-Garcés, B.L., Delgado-Huertas, A., Navas, A., Machín, J., González-Sampériz, P., Kelts, K., 2000. Quaternary paleohydrological evolution of a playa lake: Salada Mediana, central Ebro Basin, Spain. Sedimentology 47, 1135-1156. 
Walter, A. L., Frind, E. O., Blowes, D. W., Ptacek, C. J., Molson J. W., 1994. Modeling of multicomponent reactive transport in groundwater: 1. Model development and evaluation. Water Resour. Res. 30, 3137-3184.

Wells, C.R., 1923. Sodium sulphate: Its sources and uses. Bulletin 717. Washington, DC: USGS.

Wood, W.W., Sanford, W.E., 2001. Hydrogeology and solute chemistry of the coastal sabkhas aquifer in the Emirates of Abu Dhabi. Sabkha Ecosystems. 173 - 185.

Yagmurlu, F., Helvaci, C., 1994. Sedimentological characteristics and facies of the evaporite-bearing Kirmir Formation (Neogene), Beypazari Basin, central Anatolia, Turkey. Sedimentology 41, 847-860.

Yechieli Y., Wood W., 2002. Hydrogeologic processes in saline systems playas, sabkhas, and saline lakes. Earth Sci. Reviews 58, 343-365. 